\title{
DANGEROUSNESS AND CRIMINAL JUSTICE
}

\author{
Franklin E. Zimring* \\ Gordon Hawkins**
}

\section{INTRODUCTORY}

The question of dangerousness arises in criminal law whenever decisions are taken in regard to the secure confinement of offenders: decisions about remand in custody, bail, criminal sentencing, parole, providing statutory terms of imprisonment for particular offenses, and prison building programs.

Whether the likelihood of future harm should have a role in decisions about the use of imprisonment is the question we address in this article. This question is widely discussed in the literature on the jurisprudence of sentencing, and has inspired "a lot of rather uncritical and polemical literature"' and a good deal of muddled and emotive argument, with which we are not concerned. At the same time, some seriously and deservedly respected scholars have, on this topic, advanced propositions and reached conclusions, which on consideration appear plainly illogical and untenable. Their contributions to the discussion are the focus of our attention here.

The first section of this paper surveys some recent writings on the topic of dangerousness for major inconsistencies, which we regard as illuminating the special problem of dangerousness in the jurisprudence of criminal sentencing.

The second section describes the "special problem of dangerousness," for, we believe, the first time. The special problem is the fear that any admission of calculations of dangerousness into sentencing decisions will lead to an overuse of dangerousness, which may be worse than the inefficiencies and hypocrisies we confront when denying that future dangerousness is relevant to decisions about prisons.

* Professor of Law and Director of the Earl Warren Legal Institute, University of California, Berkeley. - Ed.

** Senior Fellow, Earl Warren Legal Institute; Retired Director, Institute of Criminology, University of Sydney. - Ed.

This analysis was first presented to a seminar at the Australian National Institute of Criminology in December 1985, at the invitation of then-Director Richard Harding. Earlier versions of the manuscript were read by Albert Alschuler, Michael Tonry, John Monahan, John Kaplan, Michael Laurence, and Norval Morris.

1. Symposium: Predicting Dangerousness, CRIM. JusT. ETHICs, Winter-Spring 1983, at 3, 7 (statement by Jean Floud). 
The third section attempts to reorganize the recent debate about a variety of jurisprudential and procedural aspects of dangerousness. We argue that most recent contributions to the jurisprudence of dangerousness can best be understood as attempts to limit the overuse problem discussed in the preceding section.

Under these circumstances, the substantive differences among various commentators have been overemphasized. A considerable common ground on dangerousness, particularly at the strategic level, has been overlooked. Much of the debate about dangerousness has been disagreement at the tactical level, a result of different guesses about how the world will respond to different doctrinal statements. We cannot resolve these differences, but we believe there is value in pointing out that this is where differences now lie.

\section{The JuRISPRUdence of DANGerousness}

When reading the works of an important thinker, look first for the apparent absurdities in the text and ask yourself how a sensible person could have written them. When you find an answer ... when those passages make sense, then you may find that more central passages, ones you previously thought you understood, have changed their meaning. ${ }^{2}$

Three crucial problems in the jurisprudence of dangerousness are revealed by the lengths to which scholars will go to avoid them. These problems induce an apparent tolerance of mass imprisonment without acceptable justification - what we call Dr. Messinger's dilemma. They inspire the pursuit of alternatives to imprisonment which cannot function as alternatives when restraint is an important motive for the prison's use. And they lead to the adoption of inconsistent criteria in considering dangerousness and general deterrence as justifications for imprisonment.

The devotion of a considerable amount of space to a discussion of the problematic pronouncements of other scholars possesses more justification in this context than usually obtains in academic writing. In the following pages we reproduce a variety of arguments and analyses which seem vulnerable to criticism; but the reason for this is not solely or even primarily the identification of error. The principal reason for adopting this approach is that the mistakes thoughtful scholars make when discussing dangerousness provide insight into conceptual, moral, and political difficulties encountered when predictions of future behavior are used in the determination of penal sanctions.

2. T. Kuhn, The Essential Tension xii (1977). 


\section{A. Dr. Messinger's Dilemma}

Some years ago one of us was coauthor of a book which advocated "breaking down the fusion of punishment with prison which has for so long dominated American penal policy and practice"; it proposed restricting the use of imprisonment to cases where restraint of the offender was an important function of the criminal sanction. ${ }^{3}$ A key objective of this proposal was the diminution of rates of imprisonment and prison overcrowding in America. This could be achieved, it was argued, by restricting sentences of imprisonment to cases in which they possessed a comparative advantage:

A focus on the distinctive contribution of the prison to social order, and a practical concentration on that task, is the first step toward a rational and efficient policy.

What is special about prison? What can it clearly do that other punishments cannot? It can confine people. It can keep them, at least while they are inside, from repeating the behavior against the general society that put them there in the first place. To go beyond this distinctive function is to enter a morass. ... The basis of a sensible policy is to ensure that the prison does what it can - immobilize criminals - and then to find other, acceptable measures for doing what it cannot.

... [T] he dominant justifying aim of incarceration in a prison should be incapacitation. Imprisonment should be the punishment of choice, not for all offenses as it is under current practice but primarily where it seems necessary to meet the threat of physical violence. ${ }^{4}$

Dr. Sheldon Messinger, in an otherwise generous review of the book, took issue with the proposal regarding imprisonment of the dangerous:

I disagree strongly with the principle arguably central to their proposals: namely, that the decision to incarcerate should be made to effect the "incapacitation" of offenders. ...

An incapacitative principle is a slippery slope. At the core of the notion, as the authors say, is "the prediction of future behavior." If this is what doing criminal justice is to be about, why wait for future criminals to commit crimes before incapacitating them? Surely we know the groups most likely to contain disproportionate numbers of firearm robbers, muggers, and other dangerous types. Why not incarcerate the members of these groups during their most dangerous years? There will be many false positives (i.e., wrong predictions) of course, but it seems possible that certain "forces of disorder" would be minimized by such a move.... [U]nder this plan, we wouldn't have proven that crimes were

3. M. Sherman \& G. Hawkins, Imprisonment in AMERICA 99 (1981).

4. Id. at $100-01$. 
committed by those incarcerated. But that's not what incapacitation is about: it's about future crime. ...

....

... [W]ill following their recommendations result in the reduction of pressures for added custodial facilities by partially emptying out institutions? I doubt it .....

All in all, the changed penal world that the authors' recommendations would produce would look much like the one we already have for a while. It would mean something different right from the start, however, and, in due course, those more sensitive than Sherman and Hawkins to the possibilities of a principle of incapacitation would almost surely take over. This is truly something to care about - and to fight against. $^{5}$

The heading of this subsection points up the limited nature of our objection to Dr. Messinger's position. That objection is not that he rejects incapacitation as a purpose of imprisonment: there is no dilemma, metaphoric or actual, involved in finding that present knowledge provides an inadequate basis for preventive imprisonment, or in questioning the morality of anticipatory sanctions, or in apprehension about the political implications of the acceptance of a principle of incapacitation as a justification for imprisonment. It is perfectly valid criticism of Sherman and Hawkins that in setting out to narrow the use of imprisonment in America they provided a recipe which did not narrow it enough. Indeed a radical critique of their proposal might question both the preventive justification for prison and its widespread use.

But this is not, as we read it, Dr. Messinger's position. What is both troublesome and instructive about his position, and that of many other critics of incapacitation, ${ }^{6}$ is that they simultaneously reject prevention as a purpose of imprisonment and accept prison as the primary weapon in the armory of sanctions for criminal offenses. The dilemma in political, if not logical, terms is the acceptance of the institution and the denial of the legitimacy of its unique function. It is as if someone were to acknowledge the refrigerator as the most important of kitchen appliances while denying the necessity of keeping food cold.

We do not direct attention to this anomaly to score debating points. For we have here a paradox that was not only a central feature of penological debate in the last decade, but which in the 1970s gained widespread acceptance as reformist orthodoxy. It is of sufficient significance therefore to demand critical analysis and discussion.

It is clear that opposition to preventive incarceration is deeply felt.

5. Messinger, Book Review, 1982 AM. B. Found. REs. J. 1197, 1197, $1200-01$.

6. E.g., A. von Hirsch, Doing Justice: The Choice of Punishment (1976). 
Messinger's martial rhetoric ("This is truly something . . . to fight against.") and the impassioned language of other critics of the incapacitation principle is evidence of that. Yet what is it that they are trying to avoid? Criticism is not directed at the institution of imprisonment nor at the gross overcrowding in American prisons. In rejecting Sherman and Hawkins" "key choice" in relation to future penal policy ("redefining incarceration as a tool to be used to incapacitate offenders"), Messinger does not mention those matters. The Sherman and Hawkins policy proposal certainly implies acceptance of imprisonment, but it is not that aspect which Messinger attacks.

Sherman and Hawkins argue that a policy of selective incapacitation "would reduce the number of people who are imprisoned."7 Dr. Messinger reacts as if an expansion of prison population had been proposed, and this is typical of the battle lines on dangerousness. In fact, one could argue that the adoption of dangerousness as a criterion for pretrial confinement could lead to a substantial reduction in the more than 100,000 pretrial prisoners currently held on remand. Yet no one supports it for that reason. Those who approve of preventive detention do so in the belief that many more will be confined. At the same time, those who oppose the explicit adoption of dangerousness as a criterion equate it with the expansion of prison populations and the construction of more and more prisons.

If one compares the debate over rehabilitation as the purpose and justification of imprisonment with that about preventive detention or incapacitation, a curious asymmetry is apparent. Those who espoused rehabilitation as the primary purpose of imprisonment included both those who enthusiastically approved of imprisonment and those who favored decarceration. In theory, those who embrace incapacitation should be similarly distributed between those who want more offenders imprisoned and those who want less. In practice, both those who favor and those who oppose the incapacitation principle believe that its use would lead to greater numbers being imprisoned. The Sherman and Hawkins policy proposal which associates acceptance of incapacitation with a reduction in prison populations is both novel and generally unaccepted.

\section{B. Alternatives to Imprisonment That Aren't}

The dominance of imprisonment in penal theory and practice is nowhere more evident than in the consideration of other penal measures. Ever since prison became the prime instrument of legal punish-

7. M. SHERMAN \& G. HAwKINS, supra note 3 , at 120. 
ment, other penal methods have been viewed as alternatives to it rather than as wholly independent measures. Those alternatives have not been proposed, nor have they evolved, because of their intrinsic merits; rather they originated as substitutes designed to deal with offenders for whom imprisonment was considered either unsuitable or unnecessary. Probation in the early years of this century and community corrections in the later years were principally seen by their originators as ways of keeping people out of prison. We are aware of no penal measure, with the exception of capital punishment, that has been advocated on grounds other than its superiority to and its capacity to displace prison as punishment.

It is somewhat ironic then that whatever other functions new penal measures have served in this century, and no matter how they have thrived, they have not replaced imprisonment. Our point here is not merely that large numbers of offenders continue to serve prison terms despite the availability of alternative sanctions, but rather that in all but exceptional instances the widespread use of the alternative sanctions has little or no effect on the rate at which persons are sent to prison. Thus when one compares imprisonment rates with probation rates, no inverse relationship between their use is apparent. In fact, when jail incarceration rates are also taken into account, what emerges is that rather than high imprisonment/jail incarceration rates being a corollary of low probation rates, there is a positive relation between the two. Moreover, many of those states which most frequently employ penal confinement to deal with offenders also tend most frequently to employ probation. Table A, taken from the volume that incurred Dr. Messinger's disapproval, ${ }^{8}$ shows imprisonment rates, probation rates, and jail incarceration rates for the twelve states which most frequently use imprisonment and the rates for the twelve which least frequently use it.

If established modes of nonincarcerative treatment for offenders fail to reduce the use of imprisonment, more radical alternatives also seem unlikely to perform that function. Graeme Newman's recent proposal for the revival of corporal punishment ${ }^{9}$ illustrates a number of crucial themes. For one thing, the restoration of corporal punishment is invoked, not for its own sake, but as an alternative to imprisonment. For another, and this is more remarkable than the tendency of observers to disagree with Professor Newman's suggestion, no scholar to our knowledge has taken it seriously. In a period of gross

8. Id. at 45 .

9. G. Newman, Just and Painful: a Case for the Corporal Punishment of CRiminals (1983). 
TABLE A

IMPRISONMENT, PROBATION, AND JAIL INCARCERATION RATES For the Twelve STAtes WITH Highest aNd Twelve With LOWEST IMPRISONMENT RATES

\begin{tabular}{cccc} 
States & $\begin{array}{l}\text { Imprisonment } \\
\text { Rate (1976) }\end{array}$ & $\begin{array}{c}\text { Probation } \\
\text { Rate (1976) }\end{array}$ & $\begin{array}{c}\text { Jail Incarceration } \\
\text { Rate (1972) }\end{array}$ \\
& \multicolumn{3}{c}{ Top 100,000] }
\end{tabular}

$\begin{array}{lllr}\begin{array}{l}\text { District of } \\ \text { Columbia }\end{array} & 334 & 904 & 564 \\ \text { South Carolina } & 230 & 826 & 91 \\ \text { Georgia } & 225 & 636 & 132 \\ \text { North Carolina } & 214 & 804 & 47 \\ \text { Florida } & 211 & 513 & 112 \\ \text { Maryland } & 192 & 879 & 55 \\ \text { Texas } & 167 & 860 & 84 \\ \text { Nevada } & 159 & 710 & 125 \\ \text { Michigan } & 137 & 684 & 46 \\ \text { Oklahoma } & 133 & 415 & 69 \\ \text { Virginia } & 126 & 336 & 66 \\ \text { Arizona } & 125 & 590 & 90\end{array}$

Bottom 12

$\begin{array}{llrr}\text { North Dakota } & 26 & 331 & 20 \\ \text { New Hampshire } & 30 & 438 & 37 \\ \text { Minnesota } & 39 & 374 & 15 \\ \text { Hawaii } & 41 & 478 & 28 \\ \text { Massachusetts } & 46 & 1265 & 32 \\ \text { Rhode Island } & 53 & 458 & \\ \text { Pennsylvania } & 56 & 521 & 53 \\ \text { Maine } & 57 & 261 & 24 \\ \text { Utah } & 60 & 533 & 42 \\ \text { Connecticut } & 62 & 520 & - \\ \text { Alaska } & 63 & 465 & 27 \\ \text { Vermont } & 66 & 686 & 1\end{array}$

Source: LAw Enforcement Assistance Administration, U.S. Department OF JUSTICE, PRISONERS IN STATE AND FEDERAL INSTITUTIONS ON DECEMBER 31,1976 (1978).

prison overcrowding, and in a field where almost any radical penal proposal can attract some kind of following, why is this so?

One important reason why corporal punishment would not serve and is not seen as an acceptable and viable alternative to imprisonment also explains the failure of adult probation to make a significant impression on prison populations. It is the capacity of prison, in contrast to alternative sanctions, to prevent offenders from committing offenses 
against the outside community while they serve prison terms. Insofar as that is the reason for the imprisonment of the majority of the prison population, alternative measures cannot achieve their intended impact on prison populations because they do not serve that function. This point seems so simple and so central to the question at issue that it is hard to understand how a serious discussion of alternatives to imprisonment could avoid confronting it. Yet it is avoided in contemporary literature with remarkable regularity.

As long as preventive motives account for the majority of prison sentences, institutions like probation will deal principally with offenders perceived as "nondangerous." The case is different with corporal punishment, for there is a real possibility that many offenders at the serious end of the criminal spectrum would be subjected to corporal punishment if it were available. But, as was almost always the case in the nineteenth century, they would undergo it as a supplement rather than as an alternative to imprisonment.

That, simply put, is the reason for not taking seriously the proposed reintroduction of corporal punishment, or any other nonrestraining sanction, as an alternative to imprisonment. It is only to the extent that offenders perceived as "nondangerous" are subject to prison terms that nonrestraining sanctions can compete with imprisonment on equal terms. These considerations belong at the center of any serious discussion of penal sanctions for serious offenders.

\section{Dangerousness and Deterrence}

No scholar has contributed more to the jurisprudence of imprisonment than Norval Morris has. ${ }^{10}$ On several occasions in recent years he has addressed the issue of using predictions of future behavior for determining that a criminal should be imprisoned. Initially he totally rejected "dangerousness" as a proper ground; later he accorded it a limited but significant role among the considerations relevant to the decision to imprison. Taken singly, both of Morris' arguments deserve careful attention; taken together, the path of his thinking and his change of position constituted the principal stimulus for this essay.

It will be argued that the conceptual difficulties involved in Morris' initial position on "dangerousness" can best be explained as deriving

10. See Morris, Impediments to Penal Reform, 33 U. CHI. L. REV. 627 (1966) [hereinafter Morris, Impediments]; N. MORRIS, THE FUTURE OF IMPRISONMENT (1974) [hereinafter N. MORRIS, The Future]; Morris, Punishment, Desert, and Rehabilitation, in EQUAl Justice UNDER LAW 136 (U.S. Dept. of Justice, Bicentennial Lecture Series 1976); N. MORRIS, MADNESS AND THe CRiminal LAw (1982); Morris, On "Dangerousness" In The Judicial Process, 39 REC. A.B. CITY N.Y. 102 (1984); Morris \& Miller, Predictions of Dangerousness, in 6 CRIME AND Justice: AN ANNUAL Review of Research 1 (M. Tonry \& N. Morris eds. 1985). 
from apprehension of the "political danger in the current widespread acceptance of dangerousness as a justification for imposing imprisonment or as a basis for prolonging the duration of a prison term."11 It will further be argued that, while Morris now accepts the prediction of future risk as relevant to the imposition of prison sentences, his specific proposal reflects a persistent ambivalence toward preventive confinement - an ambivalence which dominates the thinking of American scholars and policy makers in this context.

Morris' initial position on dangerousness can be found in a chapter on the justification of imprisonment in his The Future of Imprisonment:

Even when a high risk group of convicted criminals is selected, and those carefully predicted as dangerous are detained, for every three so incarcerated there is only one who would in fact commit serious assaultive crime if all three were released. ...

... [A]s a matter of justice we should never take power over the convicted criminal on the basis of unreliable predictions of his dangerousness. ${ }^{12}$

The argument and evidence in support of this position had been presented earlier in the chapter:

It is important to note that our predictions can fail in two ways and that we have developed an extremely useful technique to conceal the more troublesome failures from ourselves. First, the two paths to failure. Let us suppose that we have to predict future violence to the person from among one hundred convicted criminals, and let me invent figures that are far superior to any we can now achieve in practice. Assume that of the one hundred, we select thirty as likely future violent criminals. Despite our prediction of danger, all one hundred are either released or left at large. Their subsequent careers are then followed, and with hypothetical precision we know the results. Of the thirty we predicted as dangerous, twenty did commit serious crimes of violence and ten did not. Of the seventy we declared to be relatively safe, five did commit crimes of physical violence and sixty-five did not.

Reading [these results] one might claim, "We had 80 percent success in our prediction, successfully preselecting twenty out of the twenty-five who later committed serious crimes of violence." Not bad. Of course, we failed to select five of the one hundred who later proved to be dangerous, but that seems a minor failure compared with the twenty serious crimes we could have prevented. Note, however, that we also failed in another way. We selected ten as dangerous - as likely to commit crimes of violence - but they did not. Had we imprisoned the thirty that we predicted as dangerous, in ten cases we would have failed in our

11. N. MORRIS, THE FUTURE, supra note 10, at 72 .

12. Id. at 72-73. 
prediction by needlessly detaining them. Put more succinctly, we made twenty true positive predictions of violence and ten false positive predictions. ${ }^{13}$

There is no logical error involved in this analysis or the conclusion derived from it. But a problem arises when Morris' argument regarding the injustice of preventive confinement is contrasted with his advocacy of "a general deterrent justification for the imposition of a prison sentence."14 Regarding this criterion for imposing imprisonment, which he approves on both moral and practical grounds, he says:

The second criterion I have suggested - that of the necessities of general deterrence and the appropriateness of this offender for deterrent purposes - finds no place in current codes but remains, in my view, inescapable. It is, for example, the principle on which rests the entire structure of income tax sanctions. Not every tax felon need be imprisoned, only a number sufficient to keep the law's promises and to encourage the rest of us to honesty in our tax returns. The present arrangements for imprisoning federal tax offenders are an object lesson in the parsimonious application of general deterrent sanctions: approximately 80 million tax returns were filed in 1972; only 43 percent of the 825 individuals convicted for tax fraud were jailed. ${ }^{15}$

The nature of the problem which the comparison of Morris' two arguments entails becomes evident if the calculus employed in relation to the prediction of dangerousness is applied to the issues of both dangerousness and general deterrence, as shown in Table B.

\section{TABLE B}

\section{FAISE PREDICTION AND THE JUSTICE OF IMPRISONMENT}

\section{Dangerousness}

33

(Future Offenses)

False Positives

Total
67

$\overline{100}$
General Deterrence

$$
0
$$

100

Morris' analysis of dangerousness argues the injustice of imprisoning 100 in order to prevent transgressions by 33, finding the practice unjust no matter how much crime this strategy might prevent. In other words, the moral case against the use of predictions of dangerousness as a ground for imprisonment is based on the injustice of imprisoning those who would not offend again. Yet imprisonment to

13. Id. at 66-67.

14. Id. at 76.

15. Id. at 79 (citations omitted). 
prevent the commission of crimes by others, ${ }^{16}$ which by definition has a false positive rate of 100 percent, is approved. How can this be? If it is unjust to lock up 100 because 67 will not offend again, why isn't it more problematic to imprison 100 in order to persuade others not to commit future crime? And what is there in the nature of the debate about dangerousness which enables this paradox to be overlooked?

\section{From Basic Purposes to Limiting Principles}

One need not search far for the practical rationale underlying Professor Morris' distinction between dangerousness and general deterrence as justification for the imposition of prison sentences. Early in his discussion of the concept of dangerousness, the following passage, which is central to his rejection of dangerousness, occurs:

There is a seductive appeal to drawing a distinction between the dangerous and the nondangerous and confining imprisonment to the former. It would be such a neat trick if we could perform it: prophylactic punishment - the preemptive judicial strike, scientifically justified - saving potential victims of future crimes and at the same time minimizing the use of imprisonment and reducing the time to be served by most prisoners. But it is a trap. Social consequences are often counter-intuitive. The concept of dangerousness is so plastic and vague - its implementation so imprecise - that it would do little to reduce either the present excessive use of imprisonment or social injury from violent crime. ${ }^{17}$

Again, some pages further on he writes:

So imprecise is the concept of dangerousness that the punitively minded will have no difficulty in classifying within it virtually all who currently find their miserable ways to prison and, in addition, many offenders who are currently sentenced to probation or other community-based treatments. If one looks at the grist of the mill of city jails and state felony prisons it is hard not to drop these gnarled grains through the expansive hole of "dangerousness." 18

Many observers might think that deterrence carries both the same seductive appeal, and the same almost limitless potential for filling prisons, as dangerousness. In Britain in the late nineteenth century, the dominance of deterrence as the justifying purpose of imprisonment resulted in levels of imprisonment higher than at any other time in the country's history. ${ }^{19}$ And in America in the late twentieth century, where deterrence has been described by Morris himself as the "pri-

16. Morris "intend[s] to exclude the fear of repetition of crime by this criminal. The concept is that of general deterrence, ... the deterrence of all who might be inclined to do what he has done." Id. at 76.

17. Id. at 62 .

18. Id. at 72 .

19. M. SHERMAN \& G. HAWKINS, supra note 3, at $58,65$. 
mary and essential postulate" of our criminal justice system, ${ }^{20}$ prison populations and imprisonment rates reached unprecedented heights.

Yet it seems likely that for Morris the distinction between dangerousness and deterrence lies in the relatively overt and unambiguous character of the use of imprisonment to influence the behavior of those other than the prisoner himself. The false positive problem is an intrinsic definitional element of punishment for general deterrent purposes, and thus the need for limits on the extent and duration of penal confinement dedicated to its achievement is plainly manifest.

By contrast, what makes dangerousness peculiarly seductive, and gives rise to a special risk of limitlessness, is the ascription of dangerousness as a personal characteristic of the offender. For if dangerousness is viewed as a personal trait, this leads inevitably to the confusion of dangerousness and desert when both are animating purposes of punishment.

If dangerousness is ascribed to our hypothetical 100 offenders, this can easily be seen as an imputation of personal demerit and culpability. Even if only some of the 100 would commit further offenses, the temptation to treat all of them as future criminals is strengthened because it can also be justified as what they deserve. And this reinforcement of the grounds for penal treatment may generate an enthusiasm for confinement which in prospect justifiably alarms those familiar with American history and the current scene.

The confusion or combination of general deterrent purposes with personal guilt, on the other hand, seems less persuasive and less probable. In the case of general deterrence, the community's sense of "just deserts" or retributive justice may create a limit beyond which punishment seems unfair. But in regard to dangerousness, seen as a characteristic of the person, no obvious conflict with retributive principles is apparent. Ironically, on this view, the evident unfairness of punishment for general deterrent purposes constitutes an argument for accepting its legitimacy.

The dilemma of dangerousness, that is of confinement for the prevention of future crimes by the person confined, derives from the fact that the evident fit between means and ends, between prison and prevention, is so good that if prison is to be used in this way it will almost inevitably be overused. Moreover, the tendency to overuse is augmented by not one but two corollary features of the ascription of dangerousness to individuals. First, as already noted, viewing

20. Morris, Impediments, supra note 10, at 631 (Deterrence "figures most prominently throughout our punishing and sentencing decisions."). 
dangerousness as a characteristic of a person invites the conclusion that the personal quality of dangerousness is something for which the individual is responsible and blameworthy. Second, it is often associated with the not strictly congruent assumption that dangerousness is a permanent and immutable condition.

The tendency for dangerousness, as a criterion for sentencing to imprisonment, to generate overuse can lead to two different arguments for rejecting it. One of these arguments is principled, the other is not. The principled argument suggests that the results obtained, in utilitarian terms, will be closer to optimum when dangerousness is rejected than those which will inevitably follow if it is admitted and overused. Proponents of this argument may acknowledge that in theory the assignment of a very limited role to predictions of future behavior might produce an even better result, and yet deny the achievability of this result in the real world.

The second approach may be called the de facto argument. It conveys the kind of worldly cynicism which some American audiences admire. On this view, the best way to limit the use of preventive confinement is to prohibit it, knowing full well that the prohibition will not be fully effective. This tactic is calculated to moderate the use of preventive confinement; it is implied that such a prohibition, in its breach, will produce results preferable to either really effective prohibition or formal acceptance.

Professor Morris in The Future of Imprisonment probably subscribes to the first, or principled, rejection of preventive confinement. This is evident from his emphasis on the limited accuracy of methods of prediction of criminal behavior. But this emphasis invites the question: What difference would it make if, through the development of more refined prediction methods, it became possible to reduce the false-positive rate to one-third rather than two-thirds? There can only be a significant difference between these two states if there is an optimal use of imprisonment which could be achieved with the aid of more rigorous and accurate human science than we now have, and if the rejection of dangerousness is being defended as the lesser of evils.

It is not clear how far our ability to predict dangerousness would have to be improved to alter Morris' view. According to Andrew von Hirsch, even if, through the development of better data and more refined prediction methods, the false-positive rate could be brought down, it would make no difference: "[T] tion to predictive restraint is that it is not deserved. This objection 
stands even were the prediction of future criminality accurate."21 Despite this categorical assertion, however, it is acknowledged that predictive restraint might be necessary for "a small class of especially fearsome cases: namely, defendants who stand convicted of serious assault crimes and who have extensive records of violence."22

The pragmatic or de facto argument has not been explicitly made by anyone. But it seems to be implicit in the posture of those more sophisticated opponents of preventive detention who would not deny that prevention is in fact an element in pretrial detention but would argue that with formal acceptance its overuse would substantially increase.

Two conclusions can be drawn from the foregoing review. First, a jurisprudence of imprisonment can accommodate the kind of paralogism associated with Professor Morris' treatment of deterrence and dangerousness, and yet still result in the best achievable outcome in practice. Second, if the adoption of dangerousness inevitably tends to its overuse, the acceptability of a sentencing system that acknowledges dangerousness as a criterion depends on the design of strategies to minimize overconfinement. In fact, the definition of rules governing the use of imprisonment to incapacitate the dangerous offender becomes crucial to the case for the inclusion of incapacitation as a purpose of imprisonment. We are thus led from a review of a debate about basic purposes directly into the discussion of limiting principles.

\section{LIMiting Principles}

If limits on the overuse of predictions of dangerousness are central to concerns about the acceptance of dangerousness as a criterion for sentencing, they should play a significant role in discussions of the jurisprudence of dangerousness. In fact, limits on the use of a dangerousness criterion have been a central concern in discussions of dangerousness in the past decade, although the fact that the central concern is overuse is not explicitly acknowledged. And most of this discussion relates to the later views of scholars initially opposed in principle to the use of dangerousness at all. Frequently, as in the case of Professors Norval Morris and Andrew von Hirsch, an initial opposition to the use of preventive imprisonment is later qualified, but the same concerns that led to the rejection of a dangerousness criterion now motivate the demand for domesticating principles and procedures.

In this section, we first attempt to identify limiting principles and

21. A. von HiRSCH, supra note 6 , at 125 .

22. Id. at 126. 
procedures and then to discuss the prospects of those limitations, either alone or in combination, for facilitating a balanced use of predictions of dangerousness in criminal sentencing. Three basic tactics are identified in the recent literature for limiting the use of predictions of dangerousness: categorical exclusion, external principles of constraint, and presumptions and other allocations of the burden of proof of dangerousness.

\section{A. Categorical Exclusions}

Categorical exclusions are distinctions proponents of prediction would draw between varieties of prediction they would not allow in the jurisprudence of sentencing and those they would permit. Such a tactic is unnecessary in the context of a principled objection to all use of prediction in sentencing. If no prediction is permitted then no subcategories of prediction need to be identified for exclusion.

Almost all categorical exclusions are based on the proposition that some kinds of prediction are more prone to problematic error than others. The dividing lines to be found in the literature are various. Distinctions are drawn between group and individual predictions. For example, Norval Morris in The Future of Imprisonment described anamnestic predictions based on close observation of a particular individual's past behavior as less subject to error than statistical or categorical prediction derived from data relating to groups of offenders; Morris thought the former might "properly be relied on to determine probation and parole conditions." ${ }^{23}$ Andrew von Hirsch rejects what he refers to as "individual prediction strategies" based on data derived from samples of offenders, in favor of "a predictive strategy that is oriented to categories of criminal acts." 24 Distinctions are based on durational limits, as when very long sentences for preventive purposes are prohibited or made subject to special review. Thus it has been urged that offenders subject to sentences of extremely long duration should be provided an individualized review by an appropriate agency. 25

There are also distinctions based on the behavioral models used to establish risk, as when predictions based on clinical or medical models are excluded whereas those derived from more statistical models are

23. N. Morris, The FUTURe, supra note 10, at 32.

24. A. von Hirsch, Past or Future Crimes: Deservedness and Dangerousness in the Sentencing of Criminals 150 (1985).

25. See Zimring, Remarks of Franklin E. Zimring as Commentator, in Current Developments in Judicial Administration: Papers Presented at the Plenary Session of the American Assn. of Law Schools, December, 1977, 80 F.R.D. 147, 165 (1977). 
approved. Thus Morris and Miller distinguish predictions "based on validated actuarial evidence" from clinical predictions made "on an intuitive, untested, and unverifiable basis"; they argue that "clinical predictions of dangerousness unsupported by actuarial studies should rarely be relied on." 26 Further there are distinctions which relate to the mechanisms of review, as when parole predictions are opposed but predictions built into legislation or judicial decisionmaking are accepted. Such distinctions underlie proposals for the abolition of parole and the reallocation of the powers held by parole authorities to judges or the legislature. ${ }^{27}$

Finally, distinctions are drawn between criminal justice functions, as when preventive detention prior to conviction is rejected whereas after conviction it is approved. Thus the American Bar Association rejected pretrial preventive detention of "the dangerous defendant" on the ground that "[t]oo little is now known of the true need for preventive detention and of the predictive techniques required to operate the system with tolerable accuracy." 28 But it has accepted dangerousness as a determinative guide to the use of imprisonment, as have also the American Law Institute, the National Council on Crime and Delinquency, and two national commissions. ${ }^{29}$

While there are important differences between one topic and another, the strategic character of the categorical exclusion argument is common to all: it views one kind of prediction as less dangerous or more useful than another.

The categorical exclusion strategems share a number of common problems, including: first, insufficient evidence that the excluded techniques are specially problematic, or the permitted techniques are reliable; second, problems in policing the prohibited prediction procedures; and third, the difficulty of ensuring that the techniques of prediction permitted will not themselves be overused to compensate for the unavailability of the excluded categories.

The finding that one prediction technique is more problematic than another often seems to be based on intuitive judgment. Rarely is any solid empirical evidence adduced: there is seldom if ever evidence that reform reduces reliance on prediction of dangerousness; and never to our knowledge has the enforcement of a categorical exclusion been

26. Morris \& Miller, supra note 10 , at 48 .

27. See D. Fogel, “. . . We ARe the Living Proof . . " 192-208 (1975); Twentieth Century Fund, Task Force on Criminal Sentencing, Fair and Certain Punishment (1976).

28. Standards Relating to Pretrial Release $\S 5.5$ commentary at 69 (1968).

29. See N. MORRIS, THE FUTURE, supra note 10 , at 62 . 
conjoined with an estimate of variation in the total extent of reliance on such predictions. The second problem is more mundane but no less important; it is that of enforcing a jurisprudential prohibition, whether it be of clinical predictions or of those based on rehabilitative principles.

The third problem might be termed the hydraulic hypothesis, in that the pressure created by exorcising prediction of dangerousness by some agencies, such as parole boards or clinical psychologists, may simply raise the level of reliance on such predictions in other areas thus neither reducing the influence of prediction in the determination of sentence levels or the margins of error associated with it. Even if judges or legislators were not overusing prediction when parole boards were doing so, there is no assurance that judges and legislators will not increase predictive activity to fill the vacuum created by the cessation of parole. If other agencies assume the exercise of predictive decisionmaking to the extent that parole boards forgo it, there is no guarantee that they will not do it just as inexpediently. It might seem reasonable to expect that the fewer the agencies that can employ predictive powers the more the role of prediction in sentence determination will be reduced and the danger of overuse diminished. In fact there is no reason at all to make that assumption.

\section{B. External Principles of Constraint}

External principles of constraint neither exclude considerations of dangerousness per se nor prohibit any specific kind of dangerousness computation. Instead, predictive criteria are permitted to influence decisions but only within limits defined by other criteria. Two examples here discussed are the so-called desert limits, central to the jurisprudence of dangerousness expounded in the recent writing of Norval Morris, and the equality or parity principle which is emphasized in the arguments of other desert theorists such as Andrew von Hirsch.

Norval Morris and Andrew von Hirsch may seem to approach this question along very similar lines. In fact, the difference between their respective views is substantial. Morris stresses the importance of "the proper use of predictions of dangerousness." 30 Von Hirsch sees almost no role for it to play except in quite unique and fortuitous circumstances. Even with desert limits, dangerousness can become one of two or three major factors influencing the choice between prison and nonprison sanctions for Morris, while a superficially similar prescrip-

30. Morris \& Miller, supra note 10 , at 46. 
tion leads von Hirsch to accord dangerousness almost no practical importance.

The use of desert as an external principle of constraint is the crucial element in the revised position adopted by Norval Morris. It functions as a control on those features of predictive sentencing which led to the rejection of the dangerousness criterion per se. We cannot improve on Morris' own statement of his present position: "Punishment should not be imposed, nor the term of punishment extended, by virtue of a prediction of dangerousness, beyond that which would be justified as a deserved punishment independently of that prediction."

The principle that the maximum of punishment should never exceed the punishment deserved was earlier enunciated by Professor Morris as one of three general principles to guide the decision to imprison. He made it clear in that context that the concept of desert he was employing was not that of the pure retributivist, which involves "matching" the severity of the penalty with the offender's culpability "as related to salvation or ethics," but rather one according to which the penalty is defined by what "would be seen by current mores" as appropriate. "The concept of desert" in this sense is "limited to its use as defining the maximum of punishment that the community exacts from the criminal to express the severity of the injury his crime inflicted on the community as a condition of readmitting him to society." 32

Desert thus conceived

is, of course, not precisely quantifiable. There is uncertainty as to the judge's role in its assessment, argument as to the extent to which he ought to reflect legislative and popular views of the gravity of the crime if they differ from his own. And further, views of the proper maximums of retributive punishments differ dramatically between countries, between cultures and subcultural groups, and in all countries over time. ${ }^{33}$

Nevertheless the deserved punishment can be defined as "what is seen by that society at that time as a deserved punishment."34

The application of this concept of desert in the jurisprudence of predictions of dangerousness

depends on the recognition that there is a range of just punishments for a given offense; that we lack the moral calipers to say with precision of a given punishment, "That was a just punishment." All we can with precision say is: "As we know our community and its values, that does not seem an unjust punishment." It therefore seems entirely proper to us,

\section{Id. at 35 .}

32. N. MORRIS, THE FUTURE, supra note 10, at 60, 73-74.

33. Id. at 75-76.

34. Id. at 76. 
within a range of not unjust punishments, to take account of different levels of dangerousness of those to be punished; but the concept of the deserved, or rather the not undeserved, punishment properly limits the range within which utilitarian values may operate:

....

... [The] range of "not-unjust" punishments [is] measured in relation to the gravity of the offense and the offender's criminal record. . . . $[U]$ niversally these are the two leading determinants of what are seen as just punishments. ${ }^{35}$

It is apparent that there are some problems involved in the application of this concept of desert as a constraint on the use of predictions of dangerousness. In the first place, it is not clear how wide the "range of 'not-unjust' punishments" might be nor what limitation on the scope of predictive judgments the desert constraint would impose. As von Hirsch has somewhat misleadingly put it:

After stating that desert should be a "limiting" principle, Morris neither specifies the breadth of those limits nor suggests principles that would guide one in ascertaining them.

The failure to define the retributive constraints has worrisome implications for Morris's view of prediction. One simply does not know by how much a sentence may be increased - beyond that justified on other grounds - in reliance on forecasts of dangerousness. To say that prediction is permissible provided the sentence does not become excessive provides no guidance, if the criteria for excessiveness are left unspecified. ${ }^{36}$

This is misleading because Morris nowhere suggests that "a sentence may be increased - beyond that justified on other grounds - in reliance on forecasts of dangerousness." But it remains true that Morris' specification of desert limits provides no guidance as to what sort of restriction those limits would impose, beyond the suggestion that "a Minnesota/Pennsylvania-type sentencing system . . . gives some operative and ascertainable meaning to the upper limit of desert."37

In the second place, if the "range of "not-unjust' punishments" frequently included both prison and nonprison sanctions, dangerousness might well become the sole basis for deciding between a sentence of imprisonment and its alternatives. Since desert is only a limiting principle, within those limits cases that are alike in respect of the gravity of the offense may be treated unlike on the grounds of dangerousness. This is particularly disquieting for those who insist, as Andrew von

35. Morris \& Miller, supra note 10, at 37-38.

36. A. voN HIRSCH, supra note 24, at 141.

37. Morris \& Miller, supra note 10, at 39. The reference to a "Minnesota/Pennsylvania-type sentencing system" is to a series of guidelines, issued by an administrative agency, that specified a relatively narrow range of minimum and maximum punishment for a combination of specific offense and offender's prior criminal record. See MINNESOTA SENTENCING GuIDELINES AND Commentary (Minn. Sentencing Guidelines Commn. Aug. 1984). 
Hirsch does, that "persons whose criminal conduct is equally serious should be punished equally." 38 Indeed he makes precisely this point:

Suppose one treats desert as supplying only those outer limits - that the sentence must fall somewhere between $a$ and $b-$ and then allows the disposition to be decided within these bounds on utilitarian grounds. This would allow two offenders, whose conduct is equally reprehensible but who are considered to present differing degrees of risk, to receive differing punishments. ${ }^{39}$

And where the difference in punishment is of a qualitative nature, as between custodial and noncustodial sanctions, the perceived inequality would be very considerable.

A third problem with Morris' use of desert as an external constraint is that perceptions of dangerousness might well influence the community's perceptions of desert. It is important to consider the question of the relationship between the community's feelings about the offender's dangerousness and societal notions of desert. For in some instances dangerousness functions not merely as an influence but as the decisive factor in desert estimates. point:

A passage from Joel Feinberg's Doing and Deserving illustrates the

It may seem "self-evident" to some moralists that the passionate impulsive killer, for example, deserves less suffering for his wickedness than the scheming deliberate killer; but if the question of comparative dangerousness is left out of mind, reasonable men not only can but will disagree in their appraisals of comparative blameworthiness, and there appears to be no rational way of resolving the issue. ${ }^{40}$

To Bentham, in his Specimen of a Penal Code, it seemed self-evident that for those with "perverse anti-social dispositions ... [ [t]he punishment must be more severe."41 His justification for this was of course explicitly utilitarian: the "hardened character" or the "implacable and barbarous heart" had to be "restrained by greater terrors."42 It is by no means self-evident, however, that such additional and special punishment "would be seen by current mores as undeserved."43

Not infrequently special penalty ranges are advocated, and provided by law, because "legislative and popular views of the gravity of the crime" incorporate both estimates of the reprehensibleness of the offense and the dangerousness of the offender. There seems little

\footnotetext{
38. A. von HIRSCH, supra note 24, at 40.

39. Id.

40. J. Feinderg, Doing ANd Deserving 117 (1970) (emphasis in original).

41. 1 J. BENTHAM, THE WORKS OF JEREMY BENTHAM 167 (J. Bowring ed. 1843).

42. Id.

43. N. MORRIS, THE FUTURE, supra note 10, at 60.
} 
doubt that not infrequently perceptions of dangerousness influence the construction of penalty scales for particular types of crime; for example, those committed by peeping toms, exhibitionists, drug offenders, and some repetitive property offenders.

This is a point of some significance when desert is defined in the terms suggested by Professor Morris. Elsewhere in his writings, ${ }^{44}$ he has questioned the wisdom and desirability of protracted terms of imprisonment, but not on the ground that they might not be deserved. Nor would it be possible for him to do so on the basis of a concept of desert which merely reflects "what is seen by that society at that time as a deserved punishment." Indeed if desert is only a barometric measure of public opinion or popular prejudice, the desert limit is inherently flawed as a protection against the overuse of predictions of dangerousness.

Andrew von Hirsch's principal criticism of Norval Morris' view, which is that it "permits the infliction of unequal punishment upon those whose criminal conduct is equally blameworthy," 45 reflects a different conception of desert and of the way in which it should act as a constraint upon the use of predictions of dangerousness in sentencing. Central to von Hirsch's conception of desert is the notion of "commensurate deserts." According to von Hirsch:

The central principle of a desert rationale for sentencing is commensurability. Sentences should be proportionate in their severity to the gravity of offenders' criminal conduct. The criterion for deciding quanta of punishments should, according to this principle, be retrospective and focus on the blameworthiness of the defendant's actions. Prospective considerations - the effect of the penalty on the future behavior of the defendant or other potential offenders - should not determine the comparative severity of penalties. ${ }^{46}$

Although von Hirsch speaks of "commensurability in punishment" and of "the principle of commensurate deserts," 47 he does not appear to mean that the quantum of punishment should be strictly commensurate with the culpability of the offender, which would involve what Rupert Cross refers to as "a futile endeavor to equate incommensurables." 48 What von Hirsch appears to have in mind is proportionality, for he also refers to "the requirement of proportionate

44. E.g., N. MORRIS, The Habitual CRIMINAL (1951); N. MORRIS, The FUtURE, supra note 10.

45. Von Hirsch, Utilitarian Sentencing Resuscitated: The American Bar Association's Second Report on Criminal Sentencing, 33 RUTGERS L. REv. 772, 784 (1981).

46. A. von HiRSCH, supra note 24 , at 31.

47. Id. at 34,36 .

48. R. Cross \& A. Ashworth, The English Sentencing System 132 (1981). 
punishment" and "the proportionality principle's requirements";49 and his exegesis is principally in terms of what he refers to as "ordinal proportionality requirements." 50

Proportionality as a "determining principle" means that "comparisons of the gravity of the criminal conduct should be decisive of relative severities of punishments." 51 This is said to involve meeting two requirements: "The first is the requirement of parity. Persons whose criminal conduct is equally serious should be punished equally. The second is the requirement of rank ordering. Penalties should be graded in severity so as to reflect gradations in relative seriousness of the conduct." 52 The assessments of ordinal proportionality "rest on familiar judgments of comparative blameworthiness." 53 Adherence to these requirements would "preclude the resolution of questions of comparative punishment on grounds other than the blameworthiness of the offender's conduct." 54 In other words, it would preclude punishing a particular offender more severely than others convicted of the same offense because he is a worse risk.

Although von Hirsch sees desert as a determining principle in relation to ordinal magnitudes, he says that "it becomes only a limiting principle in deciding the system's cardinal dimensions of severity."ss The issue of cardinal magnitude is the issue "of anchoring the penalty scale by fixing the absolute severity levels for at least some crimes." 56 Because of "the greater difficulty of making cardinal desert judgments ... [t] here seems to be no crime for which one can readily perceive a quantum of punishment as the uniquely deserved one. . . The cardinal limits will necessarily be imprecise." 57 Nevertheless, von Hirsch sees that it is necessary "to establish the levels of severity appropriate for given degrees of blameworthiness. Otherwise, the crime-seriousness rankings and the punishment scale will 'float' independently of each other." 58

On the question of the limits imposed by cardinal desert considerations, what he refers to as "the Constraints of Cardinal Proportionality," von Hirsch says that a penalty scale "may infringe cardinal

\footnotetext{
49. A. von HiRsCH, supra note 24 , at 35,37 .

50. Id. at 40.

51. Id.

52. Id. (footnote omitted).

53. Id. at 43.

54. Id. at 40.

55. Id. at 39.

56. Id. at 43.

57. Id. at $43-45$.

58. Id. at 92.
} 
proportionality if its overall severities are sufficiently inflated or deflated."59 At the upper end of the scale, we have "serious crimes for which the severe penalty of imprisonment is manifestly deserved, and any lesser penalty would be disproportionately lenient." 60 At the bottom of the scale come "the lesser crimes for which imprisonment is plainly excessive. In between are the intermediate crimes." 61 In regard to the crucial issue of where the line should be drawn "so as to impose the severe sanction (imprisonment) for serious crimes and to avoid it for lesser offenses," "[c]ardinal desert considerations alone do not suffice ..., since ... [this] is in part a convention."62

It is only at this point that other "non-desert considerations" become relevant, and in particular crime prevention considerations including the possibility of incapacitation strategy. Von Hirsch's proposal in this connection appears to be that predictions of recidivism "might be helpful," but only in the context of "a categorial incapacitation strategy comporting with desert" which did not call for the differential punishment of offenders convicted of similar criminal acts. ${ }^{63}$ Thus if it is possible to identify certain crime categories, conviction of which is associated with increased rates of serious recidivism, "this might be reason itself for visiting such crimes with imprisonment - if that can be done in a manner consistent with desert principles." 64

In short, it would have to be done in such a way as not to violate parity by selecting individuals for enhanced punishment from among those convicted of a given crime, nor to breach ordinal proportionality by ordering penalties on a basis other than the seriousness of the conduct. Thus if conviction for certain crimes, e.g., burglary, indicates an increased risk of recidivism, this might warrant imposing the severe sanction of imprisonment - but only if all those individuals convicted of the same type of crime were punished equally, and at the same time persons convicted of other crimes of comparable gravity were also imprisoned, and only then.

The von Hirsch position differs from that of Morris in that equality of treatment controls the use of the incapacitative strategy. The justification for the selection of individuals for categorial incapacitation on the basis of the current-conviction offense is not extensively discussed. This may be because the circumstances required in von Hirsch's analy-
59. Id.
60. Id. at 93 (footnote omitted).
61. Id.
62. Id. at 93-94.
63. Id. at 153-59.
64. $Y d$. at $153-54$ (emphasis in original). 
sis before predictions of recidivism may be considered are likely to be extremely rare, as well as entirely fortuitous; it would only become important in comparing two offenses, each of which could be right at the margin of presumptive imprisonment.

Von Hirsch gives a hypothetical example in which robbers and burglars are both candidates for presumptive imprisonment on grounds of cardinal proportionality, although robberies have a slightly higher score on the seriousness scale. ${ }^{65}$ The problem he addresses is whether robbers only should be imprisoned or both burglars and robbers. This choice cannot be resolved by appealing to desert principles. Parity provides no guidance and rank ordering does not help. Cardinal proportionality is not precise enough to settle the question, because it merely requires imprisonment for the worst crimes and rules it out for lesser ones.

In some jurisdictions, von Hirsch suggests that prison population constraints might help to settle the issue. If not, then categorial prediction evidence might be decisive when one category had a higher rate of serious recidivism than the other. ${ }^{66}$ Curiously, the only justification for this extremely limited exception to the rule that "it is wrong to rely on utilitarian grounds to decide comparative punishments"67 appears to be that it is only a very small breach of the rule.

It has to be said moreover that the logical basis for making judgments about comparative punishments is never made wholly clear. Von Hirsch speaks, as we have noted earlier, of "familiar judgments of comparative blameworthiness." $68 \mathrm{He}$ says that the "judgments about the comparative seriousness of crimes and the comparative onerousness of punishments . . . have their roots in moral and practical judgments that ordinary persons make in everyday life."69

But about the logical status of these judgments, or of the related concept of desert, he tells us little more than that he does "not think purely subjectivist explanations - those that focus merely on others' negative feelings toward the actor, or the social functions of such feelings - are satisfactory."70 Whether they are or not, it can hardly be regarded as satisfactory merely to assert that the virtually total preclusion of incapacitative considerations in sentencing is required because of what has been called the "analyzed or ill-analyzed claim that pun-

\footnotetext{
65. Id. at $157-59$.

66. Id.

67. Id. at 171 .

68. Id. at 43.

69. Id.

70. Id. at 51 n.*.
} 
ishment is partly or wholly justified because or when it is deserved."71 That claim may not be, as recent critics have asserted, "impossible to state . . . coherently,"72 incapable of being "explained or developed within a reasonable system of moral thought,"73 or "multiply ambiguous and vague."74 But von Hirsch's statement of it does nothing to reassure us.

Von Hirsch acknowledges "the perplexities of desert."75 But in response to Francis Allen's rejection of the desert model on the ground that "the concepts of desert and commensurate penalties defy precise formulation and application,"76 he says merely that the "desert model cannot be dismissed simply by asserting that the concept is imprecise."77 The "imprecision" involved in the desert model, however, is not an incidental feature of that model. It derives from the fact that the judgments required in determining sentences which are proportionate in severity to the "gravity" or "blameworthiness" of an offender's conduct are "not merely 'difficult'; they are in principle impossible to make."78 This is hardly a matter which can be lightly dismissed as merely one of "the various unresolved theoretical issues" which need prove no obstacle to the development of "a coherent set of sentencing rules" based on a desert model. ${ }^{79}$

Here again a contrast between the constraining principles of Morris and von Hirsch is instructive. For Professor Morris, the distance between the floor and ceiling limits imposed by desert is quite considerable and therefore troublesome to those concerned about the overuse of predictions of dangerousness. Von Hirsch's range is more restricted, with the ceiling much closer to the floor, but how the limits are determined is obscure and appears arbitrary.

\section{Presumptions and the Burden of Proof}

In addition to substantive limits, a variety of procedural measures can be employed to inhibit the overuse of predictions of dangerousness. There are contrary tendencies either to overestimate the impor-

71. T. Honderich, Punishment: The Supposed Justifications 210 (1984).

72. A. KENNY, FREEWILL AND RESPONSIBILITY 69 (1978).

73. Mackie, Morality and the Retributive Emotions, 1 CRIM. JUST. ETHICs 3, 3 (1982).

74. T. HONDERICH, supra note 71, at 210.

75. Von Hirsch, Book Review, 131 U. PA. L. REv. 819, 827 (1983) (reviewing F. ALLEN, The Decline of THe Rehabilitative Ideal (1981), and M. Sherman \& G. Hawkins, supra note 3).

76. F. ALLEN, supra note 75 , at 71.

77. Von Hirsch, supra note 75 , at 825.

78. J. FEINBERG, supra note 40 , at 117.

79. Von Hirsch, supra note 75 , at 828. 
tance of procedural controls or restraints or alternatively to disregard them entirely in the context of the overuse of predictions of dangerousness. In spite of a general disregard for procedure in the jurisprudence of sentencing, a variety of special provisions relating to dangerousness have operated both in sentencing and in connection with the pretrial detention of those thought to be dangerous.

Thus by requiring the government, when seeking the preventive detention of persons thought likely to commit crimes if released before trial, both to produce clear and convincing evidence that the safety of the community or any individual would be at risk if the defendant were released, and also to overcome a number of procedural hurdles, stringent limits have been placed on pretrial detention on the grounds of dangerousness.

For example, under the District of Columbia Court Reform and Criminal Procedure Act of 1970, the Washington, D.C. courts were directed to determine and detain without bail any defendant who would endanger "the safety of any other person or the community." 80 In practice, however, the procedures for securing pretrial detention were so complex and elaborate that the impact of the preventive detention program on the city's criminal justice system was minimal. ${ }^{81}$

The Federal Comprehensive Crime Control Act of $1984^{82}$ has created a new authority to deny release to those defendants who are likely to engage in conduct endangering the safety of the community. It describes two sets of circumstances in which a rebuttable presumption of dangerousness arises, and the burden is placed on the defendant to establish a basis for concluding that there are conditions of release sufficient to ensure that he will not engage in dangerous criminal activity.

The first of these is when a person charged with a seriously dangerous offense has in the past been convicted of committing another serious crime while on pretrial release. ${ }^{83}$ The second is where the defendant is charged with certain specific felonies punishable by ten years or more of imprisonment, involving either trafficking in opiates, narcotic drugs, or other controlled substances, or the use of a firearm to commit a felony. ${ }^{84}$ In other respects, however, the procedural requirements for the pretrial detention hearing are based on those of the

80. District of Columbia Court Reform and Criminal Procedure Act of 1970, $\$ 210$, D.C. CODE ANN. § 23-1322 (1981).

81. P. Wice, Freedom for Sale: A National Study of Pretrial Release 2-5 (1974).

82. Comprehensive Crime Control Act of 1984, tit. II, 98 Stat. 1987 (1984).

83. 18 U.S.C. $\$ 3142(e)$ (Supp. III 1985).

84. 18 U.S.C. $\$ 3142(\mathrm{e})$ (Supp. III 1985). 
District of Columbia statute. ${ }^{85}$

Moreover, the Act specifically provides that the facts on which the judicial officer bases a finding that no form of conditional release is adequate to assure the safety of any other person and the community must be supported by clear and convincing evidence. ${ }^{86}$ This emphasizes the requirement that there must be an evidentiary basis for the facts that lead the judicial officer to conclude that pretrial detention is necessary. For example, evidence such as records of arrest and conviction must be presented if the criminal history of the defendant is relied on; and evidence of the specific elements or circumstances of the current offense that tend to indicate that the defendant will pose a danger to the safety of the community must be adduced, if the dangerous nature of that offense is to be the basis of detention. ${ }^{87}$

The conditions formerly governing the imposition of increased sentences for "dangerous special offenders" provide another example of control on predictions of dangerousness. In determining "dangerousness" for the purpose of the legislation it was not sufficient to produce evidence of recidivism, however serious and extensive. The attorney representing the government had to file a notice "setting out with particularity the reasons why such attorney believes the defendant to be a dangerous special offender."88

Moreover, to establish that the defendant was a special offender, it had to be shown not merely that the offender was a recidivist, but that he had previously been convicted of two or more serious offenses committed on different occasions, and that less than five years had elapsed since his imprisonment or conviction or commission of the last such offense or some other serious offense. Alternatively it was necessary to show either that his offense was committed "as part of a pattern of conduct which was criminal" and "which constituted a substantial source of his income" and "in which he manifested special skill or expertise"; or that the offense was, or was committed "in furtherance of, a conspiracy with three or more other persons to engage in a pattern of [criminal] conduct." 89

The ways in which these procedural hurdles might inhibit the overuse of predictions of dangerousness are twofold. In the first place,

85. Cf. D.C. CODE ANN. § 23-1322(c)(4)-(5) (1981).

86. 18 U.S.C. $\$ 3142$ (e) (Supp. III 1985).

87. H.R. REP. No. 98-1030, 98th Cong., 2d Sess. 22, reprinted in 1984 U.S. CODE CONG. \& ADMIN. NEWS 3182, 3205.

88. 18 U.S.C. § 3575, repealed (effective Nov. 1, 1987) by Comprehensive Crime Control Act of 1984, tit. II, $\S 212$ (a)(2), 98 Stat. 1987.

89. 18 U.S.C. § 3575, repealed (effective Nov. 1, 1987) by Comprehensive Crime Control Act of 1984, tit. II, § 212(a)(2), 98 Stat. 1987. 
the requirement of specific evidence of dangerousness might reduce the number of cases where dangerousness was erroneously found. In the second place, the special provisions and conditions, by raising the price of using predictions of dangerousness as a means of social control, would be likely to reduce the number of occasions when the government would be willing to invoke the relevant provisions, whether the dangerousness classification was correct or not. Thus, whether because fewer erroneous classifications are made or simply because fewer classifications of dangerousness (either correct or erroneous) are made, a reduction in the use of predictions of dangerousness is likely to be achieved.

\section{CONCLUSION}

All the strategems that have been arrayed in the last section have weaknesses when employed individually as a means of limiting predictive sentencing. There remains the obvious question of how effectively they might operate when used in combination with one another. A conjunction of exclusionary controls, desert limits, and procedural requirements might present a significant barrier to the overuse of prediction. Indeed in some cases it is clear that some combination is necessary. Morris' "controlling principle for the use of predictions of dangerousness," 90 for example, would obviously require more specific control mechanisms for its implementation and could only be fairly judged in that context.

It is necessary to add, as a further complexity, an emphasis not only on the structure of juristic controls but also on the spirit in which predictive sentencing is undertaken and controlled. Our text is taken from Johannes Andenaes:

As a Norwegian Supreme Court judge once said: "Our grandparents punished, and they did it with a clear conscience. We punish too, but we do it with a bad conscience." Although the institution of punishment is necessary, it is a sad necessity. ${ }^{91}$

What is required precisely in using predictions of dangerousness is an active and troubled conscience.

If the peculiar peril emphasized in Section II, that a prediction of dangerousness is taken to imply moral fault, is correlated with overconfidence in predictive judgments, then the risk of excess use is overwhelming. There is no structural mechanism which would be

90. Morris \& Miller, supra note 10 , at 2.

91. Andenaes, The Morality of Deterrence, 37 U. CHr. L. REv. 649, 653 (1970). 
adequate to stem the tide of abuse likely to flow from such a constellation.

An essential element in achieving proper limitation of the scope of predictive sentencing is an attitudinal or dispositional posture which is hard to define but not difficult to recognize in an ongoing system. A system that is skeptical about predictive capacities has less need to impose rigid restrictions on the use of predictions of dangerousness and less need to fear overuse than one in which overconfidence prevails. By contrast, widespread belief in the efficacy and legitimacy of predictive sentencing presents a situation in which a strong case can be made for the absolute prohibition of the use of predictions of dangerousness under the aegis of the criminal law. Only those systems that do not trust themselves can be trusted by others to respect the considerable limits of a jurisprudence of dangerousness. 